\title{
Mindfulness, death anxiety, and grief in a patient with metastatic cancer
}

\author{
AM Tacón* \\ Associate Professor of Health, Texas Tech University, USA
}

\begin{abstract}
An abundant literature exists as to the benefits of mindfulness-based interventions with cancer patients, yet few mindfulness interventions have been conducted about death and dying factors such as death anxiety and grief and loss. This is a case report of a modified mindfulness intervention initiated as an urgent request for a hospitalized female patient with metastatic, rapidly advancing breast cancer. Scores for death anxiety, loss and grief symptoms were obtained during the modified seven-week intervention. Objective and subjective reports indicated improvement in death anxiety, while findings were mixed on loss and grief factors.
\end{abstract}

\section{Introduction}

A diagnosis of cancer likely elicits greater distress than any other diagnosis, regardless of prognosis, for humans fear pain and death since they are threats to our human existence $[1,2]$. The combined issues of emotional pain and mortality are shared frequently by those with a chronic and/or "terminal" illness such as cancer. Indeed, loss and grief are experienced by many cancer patients as they come to grips with the disease, deal with treatment side effects, and struggle daily with a precarious future and possible death $[3,4]$. One stress intervention with abundant literature supporting its efficacy in cancer populations is the mindfulness-based stress reduction program (MBSR) [5]. Specifically, research shows MBSR programs significantly improve a broad range of psychological outcomes; that is, examples include significant reductions in stress, anxiety, cancer symptoms of distress, depression, pain anxiety and pain catastrophizing, existential well-being, and mental adjustment to cancer [4,6-9]. Accordingly, reported here is the case study of a 43-year old female in the final stages of metastatic cancer struggling with overwhelming death anxiety.

\section{Presenting Case}

An oncology surgeon in a southwestern community of approximately 250,000 approached AT (author) to discuss patient KA, a 43-year-old Caucasian female, with stage IV metastatic breast carcinoma. The patient initially presented almost two- years prior with inflammatory breast cancer, and had undergone chemotherapy, a modified radical mastectomy and radiation. The presenting concern was the patient's declining coping skills and overwhelming anxiety about disease spread and her "terminal" prognosis. KA had refused to attend group sessions with other patients or religious consultation, yet expressed interest in individual, personalized guidance or training in a mind-body strategy to reduce her stress and anxiety. The surgeon asked AT to meet with KA due to AT's training and experience in conducting Mindfulness-based Stress Reduction programs (MBSR) with chronic disease patients. The patient's medical history and current condition indicated that the disease process was aggressive and advancing rapidly, therefore, the patient's needs were considered urgent. A modified MBSR intervention, based on KA's increasingly deteriorating physical condition, was initiated immediately. Scores for death anxiety, losses, and grief were measured during the intervention.

\section{Death Anxiety}

Death anxiety can be described as a feeling of dread, apprehension or extreme concern when thinking about the process of dying or detaching from life as well as what happens after death [10]. The level of death anxiety can vary in people due to several factors; for example, personal, social, cultural and religious differences influence one's degree of death anxiety, and likewise, death anxiety negatively impacts quality of life $[10,11]$. In those with cancer, the medical team's focus is to stabilize the patient's physical condition and symptoms (relief from pain, nausea, vomiting, etc.), which unfortunately, neglects the patient's psychological suffering with death anxiety, likely decreasing the patient's limited/remaining life quality even more [10-12].

\section{Cancer and Camouflaged Loss}

It is common for cancer patients to experience a myriad of emotions when confronted with this diagnosis, as well as the difficult treatment regimens they must endure in the name of surviving this disease. As with many chronic diseases, but especially with cancer, there are physical changes and constant adaptations to treatments and side-effects that must be dealt with both physically and psychologically. Amidst these changes, a cascade of losses occurs, for example, the initial loss being that sense of wellness, independence, and energy before the symptoms.... and then the dreaded diagnosis followed typically by combined treatments of surgery, radiation or chemotherapy. Specifically, individuals with such chronic and devastating diseases like cancer can experience what is termed here camouflaged losses; that is, the perpetual stream of hidden losses lost from plain view---not openly

*Correspondence to: AM Tacón, Ph.D., Associate Professor of Health, Texas Tech University, USA, E-mail: anna.tacon@ttu.edu

Key words: mindfulness, mindfulness-based interventions, cancer, breast cancer, death anxiety, loss and grief, death and dying, mindfulness and thanatology

Received: March 28, 2018; Accepted: April 05, 2018; Published: April 10, 2018 
seen or expressed---that lay concealed and dormant in the underbrush of a patient's consciousness.

\section{Eclipsed Grieving}

Camouflaged losses may lead to an incomplete and fragmented form of grief, termed here, eclipsed grieving because the focused energy and urgency needed to attend to them is eclipsed (shadowed or blocked out) by 1) the biomedical hierarchy of priority on physical health; 2 ) the rapidly accelerated timeline for biological warfare against certain disease processes, and; thirdly, medical training is remiss in emphasizing psychosocial or "bedside" training of medical students. It is common for patients, who are worn out physically, emotionally, and spiritually, to state at times, that the cure (treatment) is worse than the disease, itself. The term, eclipsed grief is derived from patient KA's self-description:

Just when I feel the ground is back under my feet and I can let go and cry....be mad and sad at the same time... just let go and feel...A doctor walks in and says this lab work is bad or that scan showed this and my feelings get blotted out again... like a damn eclipse of the sun. I'm reeling again knocked off my feet. My need to scream gets pushed back in shadows and I am off on another roller coaster scared to death...that's what it is... no time...no time to cry about being scared to death that I am really dying...

Even in her fear...of cancer, of treatment, of dying in a rapidly changing medical context, KA seemed to understand on some basic level that holistic integration of attention and awareness is needed to process major individual losses before the next one occurs:

I get so tired of trying to keep up and deal... with every new worry the doctor talks about...I want to pull my hair out and scream LEAVE ME ALONE, so I can catch my breath... [crying] Funny thing is....I don't have any hair left and I haven't had time to know who that woman in the mirror is. No time to say goodbye to things I used to do like walk my dog or [unclear]. Things just don't stay together good. Some feelings stay above ground like feeling sorry for myself because my beautiful hair is gone, but some [feelings] go back down and hide again... Then I get hit with the next thing I'm losing out on with my daughter...doc walks in with more bad news... what a pile-up. No wonder I'm a .... mess. I don't even know me anymore and I want to cry about that. Just the time....never realized paying attention takes time.......

\section{Mindfulness and Cancer}

Kabat-Zinn's eight-week mindfulness stress reduction and relaxation program originated at the University of Massachusetts Medical Center [5]. Basically, mindfulness is cultivating awareness each present moment. It is the disciplined practice that fosters detached, nonjudgmental witnessing of thoughts, perceptions, sensations, and emotions, which provides a means of self-regulating one's arousal and awareness [5,8]. Data from a plethora of cancer studies indicate that the MBSR is effective in significantly reducing scores on stress levels and symptoms, anxiety and depression, symptoms of cancer distress, insomnia, fatigue, and mental adjustment to cancer $[4,6,8,9,13]$. A single MBSR study has examined death-related factors in women with breast cancer [4]. The purpose here is to add to the minimal literature about mindfulness effects on factors in the field of thanatology or death and dying. Due to the temporal uniqueness of this case study, no formal hypotheses were made. Based on the urgent needs of the patient and the scant mindfulness literature in thanatology, death anxiety, loss and grief scores during the intervention were viewed as positive if scores decreased from baseline.

\section{Materials and Methods \\ Design}

This intervention required a single case-study design of one 43year old female cancer patient in the final stages of metastatic disease progression. AT (author) met with KA in the patient's hospital room at a local hospital twice weekly for the intended 8-weeks of this modified mindfulness-based intervention. Assessments were collected every other week for objective measurement along with subjective patient accounts of experience.

\section{Intervention}

The modified program consisted of the first week involving introductory training about the concept of mindfulness or mindful awareness and guided instruction as to self-directed mindfulness meditation strategies (following pre-assessment measures). Based on KA's condition and discussion with the patient, mindfulness techniques of the body scan and sitting (or lying in bed) meditation were selected. The body scan involves a gradual sweeping of attention throughout the body with non-critical acceptance of sensations or feelings, and suggestions of breath awareness and relaxation. Sitting meditation involves mindful attention of the breath and nonjudgmental awareness of distractions [5]. Guided body scan and meditation "homework" CDs were provided so that KA could use them as needed. AT continued meeting with KA weekly for seven weeks to facilitate mindfulness guidance as needed. Yoga and walking meditation strategies of the traditional program were excluded due to the patient's declining physical status.

\section{Outcome measures}

Two standardized instruments were administered before (pre) for baseline and every other week during the modified intervention to evaluate mindfulness effects on the below outcomes.

\section{Death anxiety}

Templer's internationally known reliable and valid 15-item Death Anxiety Scale (DAS) was used $[14,15]$. This measure has been the most historically used instrument to assess death-related anxiety. The DAS has been translated and validated in at least 26 countries and translated alone into approximately 54 languages [16-18]. The DAS primary format is a dichotomous scale of the 15 items on a two-factor model of death anxiety with a true-false format, thus, scores range from $0-15$ with higher scores indicating greater anxiety. This is the version used for this case report, even though the DAS also can be used in Likert format.

\section{Loss and grief scales}

Section B of the Grief Diagnostic Instrument (GDI) was used to determine endorsed or identified categories of loss [19]. This section was done verbally per KA's wishes, since talking was less taxing than written format. For purposes here, the number of identified losses will be reported. Section C of the Grief Diagnostic Instrument (GDI) was used to assess grieving symptomatology [18]. The GDI was developed for use in medical contexts. The grief scale consists of 16 items that measure grief symptoms on a 4-point Likert scale for possible high range of 48 , higher scores indicating greater severity of grief. The items meet requirements for measuring grief: they comply with the recognized principles for grief measurement, and tap the emotional, physical, social, and cognitive domains affected by grief. The summed grief severity score ratings consist of the following: mild grief $=1-17$, moderate grief $=18-22$, and severe grief $=>22[18]$. 


\section{Outcome Results}

Changes across measurement periods were considered positive if scores shifted in directions of beneficial patient improvement. The tracking of summary scores every other week for death anxiety (DAS), the number of identified losses, and grief scores are presented in Table 1.

\section{Death anxiety}

The baseline score for death anxiety objectively supported the subjective descriptions of KA, nurses, and the surgeon, that is, the patient feeling totally overwhelmed by the idea of impending death as indicated by the highest possible score of 15 on the DAS. A trend was revealed of decreasing death anxiety scores, which was consistent with subjective accounts of reduced stress and anxious preoccupation by KA as well as observations by nursing staff.

Additionally, display of the data from Table 1 is presented in Figure 1 to show scores in visual form.

\section{Losses and grief}

Identified losses decreased as did grief scores, even though grief scores remained severe in range except for the fifth week. An interesting trend was observed for the number of identified losses and grief score severity that was not present with death anxiety scores. Specifically, both sets of data showed a reduction trend until near the end of the intervention. Grief scores remained severe except for the fifth week. After that time, an upward shift occurred with higher scores returning by the last week for both losses and grief symptoms.

\section{Subjective Summary}

Each week, the patient (and observing nurses) verbalized an increasing calm and peacefulness. During discussions, KA continued to report feeling more grounded each week. She noted than whenever she started feeling paralyzed with anxiety, she would listen to one of the homework CDs or practice a mindfulness strategy, which helped her regain a sense of being anchored; for example, focusing on the inhale and exhale of the breath without judgment in a given moment. KA was fully aware that the reality-based reactions she was experiencing of advancing cancer were always present and part of her, but she could

Table 1. Outcome Summary of Scores by Week

\begin{tabular}{|c|c|c|c|}
\hline Weeks & DAS & \# Losses & Grief \\
\hline Week 1 & 15 & 17 & 35 \\
\hline Week 3 & 11 & 13 & 27 \\
\hline Week 5 & 8 & 11 & 20 \\
\hline Week 7 & 7 & 14 & 25 \\
\hline
\end{tabular}

Weekly Outcomes: DAS, Losses, and Grief

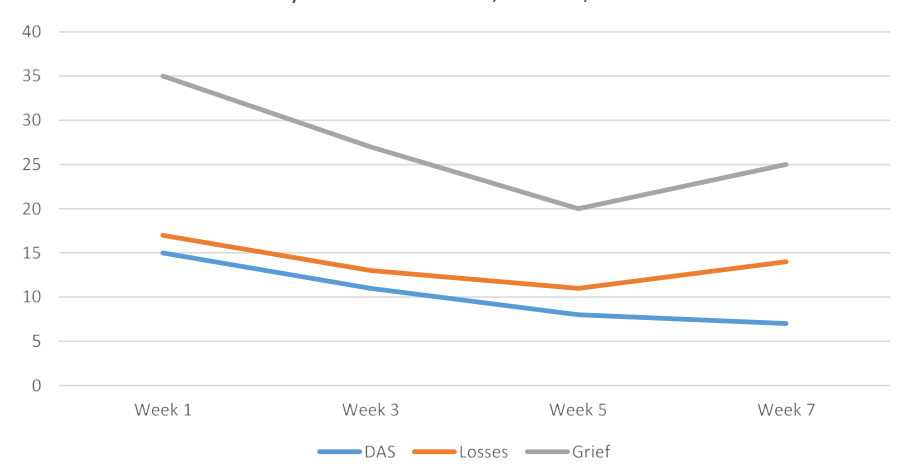

Figure 1. Scores for DAS, Losses, and Grief by week. now witness what was happening without being engulfed by the fear or being swept away by the emotionality of what was occurring. Nursing staff commented to AT about the patient's increasing equanimity during weekly visits after beginning the mindfulness sessions. During the $7^{\text {th }}$ week, KA informed AT that she no longer needed the mindfulness program, returned the $\mathrm{CDs}$, and asked to complete the last set of measures. In general, the objective scores matched the verbal and/or subjective accounts.

\section{Discussion and Conclusion}

This is the first known specific case report of an urgent modified mindfulness intervention in a 43-year old female with aggressive, metastatic breast cancer. This modified intervention was begun due to the urgent need of patient, KA, with her rapidly deteriorating condition and "terminal" prognosis. Objective data from scores as well as medical staff observations proved consistent with KA's subjective reports of decreasing death anxiety preoccupation and improved coping with losses and grief of such losses. Previous research indicates that primarily self-directed mindfulness training can have a meaningful impact on both subjective and objective health outcomes [20]. During the seventh week, KA calmly stated that she was ending the intervention and visits, thanked AT warmly, and returned the homework CDs. The following [eighth] week, AT was notified that KA had expired or died. While death anxiety scores decreased, a notable shift in loss and grief scores were observed.

Decreasing scores in the number of identified losses and severity of grief symptoms began an upward swing as documented from the $5^{\text {th }}$ to the $7^{\text {th }}$ week of data collection. KA died the very next week after discontinuing the program. A possible explanation of speculation that is known to hospice nurses is a phenomenon called Nearing Death Awareness or NDA [21-23]. Nearing death awareness is part of the dying process; indeed, it is estimated that up to $60 \%$ of terminal patients show signs of NDA immediately prior to death [21-23]. To what degree mindfulness-based awareness may have influenced NDA cannot be known, yet perhaps this may have impacted the scores of loss and grief. Empirical support is beyond the data of this case study and will never be known with certainty. Despite the World Health Organization's recommend-dations that nursing practices should focus on individuals in their existential totality, most patient care remains focused on the physical; psychological needs receive less attention [12]. However, with health care now burdened with chronic as opposed to acute illnesses of the past, medical teams of the future will need to address issues of death and dying in chronic populations.

\section{References}

1. National Cancer Institute (1997). 'Cancer Facts,' American Cancer Society, Washington, D.C.

2. Holland JC, Rowland JH (1989) Handbook of psychooncology: Psychological care of the patient with cancer. New York: Oxford University Press.

3. Breivik H, Cherny N, Collett B, de Conno F, Filbet M, et al. (2009) Cancer-related pain: a pan-European survey of prevalence, treatment, and patient attitudes. Ann Oncol 20: 1420-1433. [Crossref]

4. Tacón AM (2011) Mindfulness: Existential, loss, and grief factors in women with breast cancer. J Psychosoc Oncol 29: 642-646. [Crossref]

5. Kabat-Zinn J (1990) Full catastrophe living: Using the wisdom of your body and mind to face stress, pain, and illness. Dell, New York, NY.

6. Carlson LE (2016) Mindfulness-based interventions for coping with cancer. Ann N Y Acad Sci 1373: 5-12. [Crossref]

7. Creswell JD (2017) Mindfulness Interventions. Annu Rev Psychol 68: 491-516. [Crossref] 
8. Tacón AM (2013) Present moment effects: Pain, distress, and cancer. Advances in Cancer: Rsh \&Treat 1: 1-11.

9. Rouleau CR, Garland SN, Carlson LE (2015) The impact of mindfulness-based interventions on symptom burden, positive psychological outcomes, and biomarkers in cancer patients. Cancer Manag Res 7: 121-131. [Crossref]

10. Firestone R, Catlett J (2009) Beyond death anxiety: Achieving life-affirming death awareness. New York; Springer Publishing.

11. Bahrami N, Moradi M, Soleimani M, Kalantari Z, Hosseini F (2013) Death Anxiety and its Relationship with quality of life in women with cancer. Iran J Nur 26: 51-61.

12. Mansori YK, Dolatian M, Shams J, Nasiri M (2017) Relationship between Death Anxiety and Spiritual Well-Being in Patients with Gynecologic Cancer. Adv Nurs Midwifery 27: 28-34.

13. Tacón A, Caldera Y, Ronaghan C (2005) Mindfulness, psychosocial factors and breast cancer. J Ca Pain Symptom Palliat 1: 45-54.

14. Templer DI (1970) The construction and validation of a Death Anxiety Scale. J Gen Psychol 82: 165-177. [Crossref]

15. Lonetto R, Templer D (1986) Death anxiety. Washington; Hemisphere Pub.
16. Beshai JA, Naboulsi MA (2004) Existential perspectives on death anxiety. Psychol Rep 95: 507-513. [Crossref]

17. Saleem T, Gul S, Saleem S (2015) Death anxiety scale: Translation and validation in patients with CVD. Professional Med J 22: 723-732.

18. Templer D, Awadalla A, Al-Fayez G, et al. (2006) Construction of a death anxiety scaleextended. Omega 53: 209-226.

19. Clark S, Marley J, Hiller J, Leahy C, Pratt N (2006) A Grief Diagnostic Instrument for General Practice. Omega-Journal of death and Dying 52: 169-195.

20. Oberg EB, Rempe M, Bradley R (2013) Self-directed Mindfulness Training and Improvement in Blood Pressure, Migraine Frequency, and Quality of Life. Glob $A d v$ Health Med 2: 20-25. [Crossref]

21. Callahan M, Kelley P (1992) Final gifts: Understanding the special awareness, needs, and communications of the dying. New York: Poseidon Press.

22. Mazzarino-Willett A (2010) Deathbed phenomena: its role in peaceful death and terminal restlessness. Am J Hosp Palliat Care 27: 127-133. [Crossref]

23. Lokker ME, van Zuylen L, Veerbeek L, van der Rijt CC, van der Heide A (2012) Awareness of dying: it needs words. Support Care Cancer 20: 1227-1233. [Crossref]

Copyright: $\odot 2018$ Tacón AM. This is an open-access article distributed under the terms of the Creative Commons Attribution License, which permits unrestricted use, distribution, and reproduction in any medium, provided the original author and source are credited. 